\title{
浅谈音乐教学中如何培养音乐能力
}

\author{
曾庆圆 \\ 云南经济管理学院 \\ DOI:10.32629/er.v2i5.1845
}

[摘 要] 音乐是实践性很强的学科,其教学的所有内容都具有体验性和操作性,不仅包括音乐知识传授, 音乐技能训练这些外 显的方式, 尤为重要的是体现在音乐感受上, 也就是体验的方式。因此, 音乐能力的培养应注重激发学生的音乐兴趣、情感、发 声和思维。基于此,本文结合高职院校中钢琴教学如何培养学生音乐能力进行探究。

[关键词] 钢琴教学; 音乐能力; 培养方法

钢琴作为音乐中最具综合因素的一门学科, 是音乐教 学中最基础的一门专业学科。音乐专业中的音乐表演, 音乐 教育, 音乐创作学科都离不开钢琴教学, 因此在钢琴教学中 提高学生的音乐能力尤为重要。钢琴课是高职音乐专业和 学前专业的必修课, 该专业的学生通过钢琴技能的学习来 提高对音乐的认识, 以便在以后的工作中通过该技能来进 行教学。

1 高职高专钢琴教学中对学生音乐能力培养的重要作用

1.1 培养学生的音乐能力有利于提高课堂的实效性

高职高专学生的身心发展逐渐成熟, 所以, 对于音乐的 理解能力和观察能力都有所提高。另外, 高职高专学生学习 的积极性和主动性也比较强, 一般了解乐理基础知识以后都 可以运用学过的知识提高对音乐作品的理解。但是, 想要提 高学生的音乐综合能力, 教师就应该根据每个学生的具体情 况和教材的要求有针对性地采取措施, 提高学生的音乐综合 能力和素养, 进而提高钢琴课的教学质量。

1.2 培养学生的音乐能力有利于提高学生的思想情感

在高职高专钢琴教学中, 主要分为演奏技巧和音乐能力 两方面内容。多数教师在进行演奏技巧教学的时候都是机械 性地对学生进行训练来提升学生的钢琴演奏水平。但是学生 的钢琴演奏能力是需要在日常学习和练习中逐渐提高的。音 乐能力主要是学生通过钢琴演奏, 进而客观、准确地来把握
音乐作品的内容。所以, 增强对学生音乐能力的培养非常重 要, 它能够提高学生思想情感, 使学生和作品作者达到思想 上的共鸣。

\section{2 音乐教育专业的钢琴教学现状}

高职院校在培养音乐人才方面, 受到专业音乐学院的影 响, 模仿专业性院校, 导致师生都形成错误的意识。大部分的 高职院校教师将学生当做钢琴家来进行培养, 造成教师只是 单纯的重视学生对高难度曲目的演奏, 直接忽视培养学生的 即兴伴奏以及歌曲弹唱等基本能力。导致学生仅仅会弹奏具 有固定五线谱的曲目, 针对简单的简谱歌曲无从入手的现 象。教育部门针对高职院校的人才培养的问题, 明确指出高 职院校的培养人才的目标是培养适合社会发展的专业技术 人才。可是从现如今的高职院校的音乐人才培养形式上来 看。明显的与教育部门的要求相向而行。因此, 高职院校要 努力转变教育观念, 增强对学生音乐素质与音乐能力的培养 力度。

3 在钢琴教学中如何培养学生的音乐能力

3.1 注重对学生音乐感受能力的培养

3. 1.1 站在节奏角度

节奏是构成一部音乐作品的灵魂, 也是塑造音乐形象的 关键要素。各种音乐元素构成一部优秀的音乐作品, 并形成 个性鲜明的主题, 在特定的指令下, 有规律地展开运动。构成
从企事业单位、其他高校、科研机构调入的教师相对较少, 通过调查出现这种情况的原因, 积极开发多渠道吸引优秀教 师。制定职业院校教师素质提高计划, 引领带动各地建立一 支技艺精湛、专兼结合的双师型教师队伍。

\section{[参考文献]}

[1]崔勇,沈媛元. 新时代教师的定位与内生动力激发 [J]. 教育科学论坛,2019,(10):61-66.

[2]路明兰.高职院校教师激励机制存在的问题及对策 [J].河南教育学院学报(哲学社会科学版),2008,(05):88-90.

[3]彭国平.高职 “双师型” 教师的自我激励问题研究 [J]. 职业教育研究,2009,11(12):72-73.

[4]周科.中等职业学校教师激励措施研究 [D]. 重庆大

\section{学,2017,(12):48.}

[5]郭攀. 中学教师激励问题与对策研究 [D]. 江苏师范大 学,2017,(09):70.

[6]姜小纳.中职学校教师激励机制探究 [J].继续教育研 究,2013,(10):67-68.

作者简介：

张友芬(1961--), 女, 天津人, 汉族, 本科学历, 高级讲师, 研 究方向, 人力资源管理。工作单位: 天津市仪表无线电工业 学校。

\section{课题项目:}

中职院校教师队伍建设激励机制研究(XHXB2018B128)。 
一部音乐作品需要三大基本要素。一是节奏, 二是旋律, 三是 和声。它们之间相互影响, 不是作为一个独立的个体而存在。 其中, 无论是和声还是旋律, 都依附于节奏。换言之, 一部音 乐作品缺乏节奏, 就不能称之为音乐。因此, 对于教师而言, 应引导学生展开对音乐节奏的分析, 从而进一步加深对音乐 的理解。在具体教学中, 教师应采取有效措施培养学生的律 动感, 并引导学生正确区分节奏与节拍。尤其是在圆舞曲、 小步舞曲中, 应引导学生重点把握对此类舞曲的节奏分析。 在弹奏过程中, 学生只有把握节奏分组和节奏重音之后, 才 能增强弹奏声音的活力。

\section{1.2 站在速度角度}

速度对于音乐的影响较大。所谓速度是指音乐进行的快 慢。速度可以分为三类, 一是快速, 二是慢速, 三是中速。一 般而言, 快速表现情绪的欢快; 中速表现情绪的平和; 慢速 表现情绪的沉重。除此之外, 速度与内容之间的关联性较大。 音乐作品的基本速度受结构、内容等因素影响。从某种意义 上来讲, 速度是为情感服务的。在弹奏时, 运用不同速度演绎 同一首乐曲, 会使该乐曲在形象、情绪、情感上有所不同。 因此, 教师应引导学生注意把控乐曲的速度, 并在关注乐曲 基本速度的同时分析速度的变化情况, 不能在弹奏过程中随 意更改音乐速度, 否则扭曲音乐作品本身的情绪和形象。对 于学生而言, 应依据作品要求展开钢琴弹奏, 进而提高钢琴 弹奏的实效性, 同时也是提高自身音乐能力的关键。

3.2 在钢琴教学中培养学生对音乐的理解能力

要培养学生对音乐的感受能力必须在对音乐理解能力 的基础上进行, 不理解此音乐的内涵就没法去感知, 把握。教 师通过教学让学生聆听认识音乐元素后, 再从作品的各个方 面去分析才能真正掌握一首作品的含义。例如作品的创作背 景、风格、作品内容、作者的经历或者音乐的结构、音乐的 语种、作者创作手法、音乐的艺术特色等都需要全面分析才 能理解这首作品进而进入作品意境来表达作品, 提高钢琴演 奏的感染力。在教学中培养学生理解音乐的能力有多种, 例 如在课程开始设置问题引导学生进入本节课, 带着问题去学 习一般会收到良好的效果, 通过问题引导学生对音乐的表面 理解再慢慢层层深入走向对音乐的本质理解。在此教学法中 教师可以多鼓励学生大胆地去想象, 欣赏, 进而得到答案。这 样的课堂模式可以提高学生学习的积极性, 提高学生的创新 能力和自信心, 学生在此过程还会积极展示自己的表演, 在 学生对音乐作品进行赏析时还可以加深对歌曲的认知, 进而 提高学生的综合能力。

3.3 在钢琴教学中培养学生对音乐的表现能力
音乐是一种语言艺术, 是人们感情的一种表现。钢琴的 演奏不仅仅是一种表演, 更是人们利用钢琴来表达感情的一 种艺术方式, 因此对音乐本质内涵的理解是钢琴演奏的基 础。高职教师在讲课时要培养学生树立正确的三观, 让学生 意识到钢琴的演奏是对音乐本质的深度理解。教师在教学中 仅仅培养学生对音乐的感受能力和理解能力是不能达到学 生对音乐的真正理解, 不能提高学生的综合音乐素养。教师 要积极鼓励学生勇敢的表现, 学生只有感兴趣具有强烈的表 现欲望才能认真去弹奏, 才能感知和理解作品中包含的意境, 进而表达出自己的情感和张力。钢琴是一种具有强烈感染 力的乐器, 教师要想培养学生弹奏出优美的歌曲就要培养 学生的兴趣爱好, 让学生发自内心的愿意去唱歌, 听歌, 弹 奏音乐。

3.4 提高钢琴教学中的音乐能力需要培养学生处理好音 乐旋律和伴奏的关系

节奏、旋律、和声是音乐组成的三要素, 情感是保证歌 曲美妙的重要条件。一场完整美妙的钢琴演奏也体现了音乐 能力的高低, 高职教师平时多为学生提供演奏的机会, 为提 高学生的音乐表现能力提供保障。想要表现音乐, 就需要先 对音乐进行深入的了解。学生可以通过聆听各种不同风格的 歌曲, 切身地感受歌曲中的变化; 教师可以适时地引导学生 进行歌曲伴奏的分析研究, 潜移默化影响学生对音乐的鉴 赏、理解能力。钢琴弹奏技法是表现音乐形象最重要的环节, 这并非是一朝一夕就能够掌握的, 需要进行长期的练习, 才 能提高弹奏技能。

\section{4 结束语}

作为音乐教师, 应该有一套新的教学模式, 即要有一定 的专业知识和技能, 也要有良好的文化知识; 既要掌握素质 教育的理论和教育教学的方法, 又要不断的培养学生的能力 使他们在感知, 想象思维, 科学的发声法, 情感教育、互动合 作以及欣赏这几方面不断的提高并能有机联系在一起, 这不 断的促进和提高学生的智力、技能、思维、和兴趣以及音乐 能力。

\section{[参考文献]}

[1]沈玉国.中职学前教育专业音乐能力的培养[J].教 育,2018(14):18.

[2]张磊.论高职音乐教育专业学生音乐教学能力的培养 [J].北方音乐,2018(06):38.

[3]雷晓希.培养音乐能力提高音乐素养[J].考试周 刊,2017(03):99. 